\title{
Factors affecting long term survival following resection for lung cancer
}

\author{
K Al-Kattan, E Sepsas, E R Townsend, S W Fountain
}

\begin{abstract}
Background - Survival following pulmonary resection for primary lung cancer is considered to be principally dependent on the clinical stage of the disease. A study was undertaken to verify this and to identify other contributing factors.

Methods - The case records of all patients who underwent surgery for lung cancer over a two year period between January 1987 and December 1988 were reviewed retrospectively.
\end{abstract}

Results - One hundred and forty seven lobectomies and 60 pneumonectomies were performed with $2.8 \%$ and $5.3 \%$ operative mortality, respectively. Squamous carcinoma was the commonest pathology $(60 \%)$ followed by adenocarcinoma $(30 \%)$. The overall five year survival was $45.5 \%$ (95\% CI $44.1 \%$ to $57.9 \%$ ). There were 123 patients with stage I disease, 40 with stage II, and 37 in stage IIIa with five year survival of $59.4 \%$ (95\% CI $50.8 \%$ to $68 \%$ ), $30 \%$ (95\% CI $15.9 \%$ to $44.1 \%)$, and $16.2 \%(95 \%$ CI $3.5 \%$ to $31 \%$ ), respectively. There were no differences in survival with respect to sex, extent of resection, or cell type. In patients with stage II disease the five year survival of those with T1 lesions $(50 \%, 95 \%$ CI $37.3 \%$ to $62.9 \%$ ) was better than those with T2 $(28.1 \%, 95 \%$ CI $16.9 \%$ to $39.3 \%)$. Of eight patients over the age of 70 with stage IIIa disease none survived more than 24 months.

Conclusions - Stage at operation is the most accurate predictor of long term survival in early lung cancer and surgery remains an effective treatment, particularly in stage I and II disease. Further study is needed to assess the prognostic value of subdividing stage II disease into $\mathrm{T} 1$ and T2 lesions. Major resection for locally advanced disease in older patients may be relatively ineffective.

(Thorax 1996;51:1266-1269)

Keywords: lung cancer, survival, staging

Thoracic Surgery

Harefield Hospital,

Uxbridge, Middlesex

UB9 6JH, UK

K Al-Kattan

E Sepsas

E R Townsend

$S$ W Fountain

Correspondence to: Mr S W Fountain.

Received 21 September 1995

Returned to authors

12 December 1995

Revised version received

24 June 1996

Accepted for publication

28 June 1996 a significantly better prognosis than those with invasive tumours and mediastinal lymph node involvement (stage IIIa).
In this study we have reviewed retrospectively all patients who underwent pulmonary resection for primary lung cancer at our institution over a two year period at least five years ago to confirm the above relationship and to identify any other factors important in predicting actual long term survival.

\section{Methods}

Two hundred and seven patients with primary lung cancer underwent pulmonary resection between January 1987 and December 1988. There were 143 lobectomies and 57 pneumonectomies with an operative mortality of $2.8 \%$ and $5.3 \%$, respectively. Complete follow up was available for all 200 patients who survived surgery, of whom 142 were men, and the mean age was 64 years (range 39-83). Squamous cell carcinoma was the commonest cell type being present in 120 patients $(60 \%)$ followed by adenocarcinoma in $61(30 \%)$.

There were 123 patients ( 83 men) with stage I disease (34 T1N0 and 89 T2N0) (see table 1 for explanation of classification) with a mean age of 64.8 years (range 39-82). Pneumonectomy was performed in 27 patients (five for T1N0 and 22 for T2N0) while lobectomy was

Table 1 New intermational TNM staging system

\begin{tabular}{llll}
\hline Stage & $T$ & $N$ & $M$ \\
\hline I & T1 & N0 & M0 \\
& T2 & N0 & M0 \\
II & T1 & N1 & M0 \\
& T2 & N1 & M0 \\
IIIa & T3 & N0 & M0 \\
& T3 & N1 & M0 \\
& T1-3 & N2 & M0 \\
IIIb & Any T & N3 & M0 \\
IV & T4 & Any N & M0 \\
& Any T & Any N & M1
\end{tabular}

Primary tumour $(\mathrm{T})$

$\mathrm{T} 1=\mathrm{A}$ tumour that is $3.0 \mathrm{~cm}$ or less in greatest dimension, surrounded by lung or visceral pleura, and without evidence of invasion proximal to a lobar bronchus at bronschoscopy. $\mathrm{T} 2=\mathrm{A}$ tumour more than $3.0 \mathrm{~cm}$ in greatest dimension, or a $\mathrm{T} 2=\mathrm{A}$ tumour more than $3.0 \mathrm{~cm}$ in greatest dimension, or a tumour of any size that invades the visceral pleura or has associated atelectasis or obstructive penumonitis extending to the hilar region. At bronchoscopy the proxinal extent of demonstrable tumour must be within a lobar bronchus or at least $2.0 \mathrm{~cm}$ distal to the carina. Any associated atelectasis or obstructive pneumonitis must involve less than an entire lung. T3 = A tumour of any size with direct extension into the chest wall, diaphragm or the mediastinal pleura or pericardium without involving the heart, great vessels, trachea, oesophagus or vertebral body, or a tumour in the main bronchus within $2 \mathrm{~cm}$ of the carina.

$\mathrm{T} 4=\mathrm{A}$ tumour of any size with invasion of the mediastinum or involving heart, great vessels, trachea, oesophagus, vertebral body or carina or the presence of malignant pleural effusion. Node involvement $(\mathbf{N})$

$\mathrm{N} 0=$ No demonstrable metastasis to regional lymph nodes $\mathrm{Nl}=$ Metastasis to lymph nodes in the peribronchial or ipsilateral hilar region, or both.

N2 = Metastasis to ipsilateral mediastinal and subcarinal lymph nodes.

N3 $=$ Metastasis to contralateral mediastinal or hilar lymph nodes or to ipsilateral or contralateral scalene or supraclavicular lymph nodes. 
Table 2 Histological classification of 200 patients

\begin{tabular}{|c|c|c|c|c|c|c|}
\hline Stage & $\begin{array}{l}\text { Squamous } \\
\text { carcinoma }\end{array}$ & Adenocarcinoma & $\begin{array}{l}\text { Large } \\
\text { cell }\end{array}$ & $\begin{array}{l}\text { Small } \\
\text { cell }\end{array}$ & $\begin{array}{l}\text { Bronchus/ } \\
\text { alveolar }\end{array}$ & Total \\
\hline $\begin{array}{l}\text { I } \\
\text { II } \\
\text { IIIa } \\
\text { Total }\end{array}$ & $\begin{array}{r}75 \\
23 \\
22 \\
120\end{array}$ & $\begin{array}{l}38 \\
10 \\
13 \\
61\end{array}$ & $\begin{array}{r}6 \\
5 \\
0 \\
11\end{array}$ & $\begin{array}{l}4 \\
1 \\
2 \\
7\end{array}$ & $\begin{array}{l}0 \\
1 \\
0 \\
1\end{array}$ & $\begin{array}{r}123 \\
40 \\
37 \\
200\end{array}$ \\
\hline
\end{tabular}

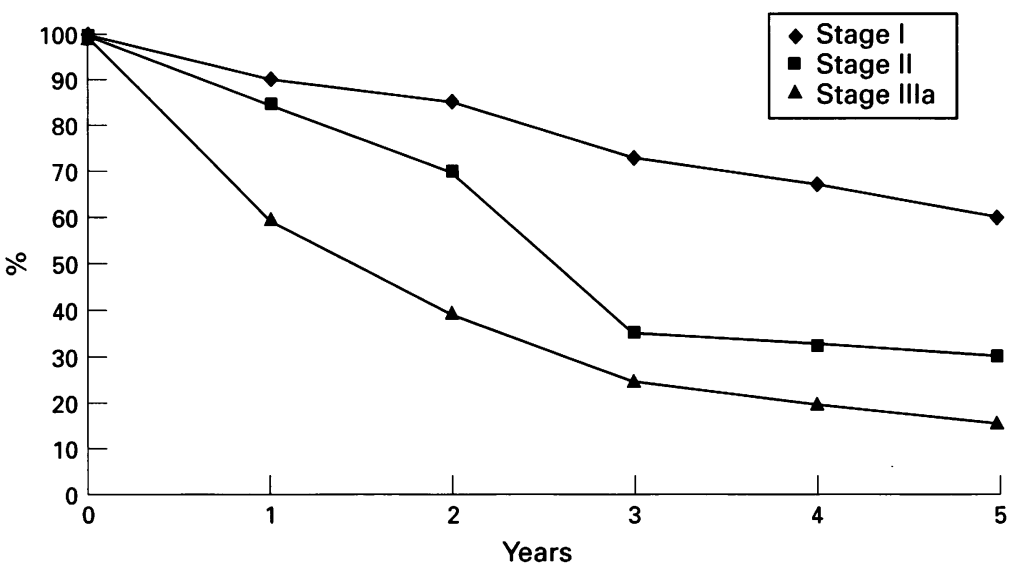

Figure 1 Survival curves in patients with stage I, II and III lung cancer.

performed in 96 (29 for T1N0 and 67 for T2N0). Twenty three patients (19\%) were asymptomatic; in those with symptoms cough $(64 \%)$ and haemoptysis (49\%) were the most common complaints. Forty patients (31 men) with a mean age of 61.4 years (range 40-83) had stage II disease (eight T1N1 and $32 \mathrm{~T} 2 \mathrm{~N} 1$ ) and 37 patients $(28$ men) with a mean age of 65 years (range 54-74) had stage IIIa disease.

The histological classification of each stage is shown in table $2 . \mathrm{N} 2$ disease was diagnosed postoperatively (from the pathological specimen) in 28 cases of which 14 were squamous cell, 12 adenocarcinomas, and two small cell carcinoma. The small number of patients with small cell carcinoma $(n=7)$ who underwent surgery did so either because they were known to have stage I disease, or the histology was unknown at the time of operation, or the cell type of the preoperative biopsy specimen proved to be incorrect.

All patients were assessed preoperatively by computed tomographic (CT) scans or mediastinal exploration with lymph node biopsy, or both. No patients with preoperatively proven N2 disease or stage IIIb disease underwent surgery. Posterolateral thoracotomy was the standard method of surgical access and the extent of resection was dictated by operative findings. Formal clearance of all mediastinal lymph nodes was not undertaken but it was standard practice to resect any abnormal looking nodes and routinely to sample nodes immediately proximal to the resection margin for example, interlobar nodes at lobectomy and subcarinal and paraoesophageal nodes at pneumonectomy. Sixteen of the 57 pneumonectomies required intrapericardial dissection. Lobectomy with chest wall resection was performed in six patients with stage IIIa disease and sleeve lobectomy was necessary in three cases.
No protocol for preoperative or postoperative adjuvant therapy was in operation at the time of this study. Some patients with stage IIIa disease were referred for postoperative radiotherapy either because of chest wall or mediastinal lymph node invasion, but this was at the discretion of the operating surgeon.

Complete follow up was available for all patients for 60 months.

\section{STATISTICAL METHODS}

All values are represented as means and survival analysis was calculated using the Kaplan-Meier product limits method with $95 \%$ confidence interval for survival function. The log rank test was used to calculate the difference between survival curves. The Student's $t$ test was used to test the difference between groups, a $\mathrm{p}$ value of $<0.05$ being considered significant.

\section{Results}

In the 123 patients with stage I disease the three and five year survivals were $72.5 \%(95 \%$ CI $64.3 \%$ to $80.7 \%)$ and $59.4 \%(95 \% \mathrm{CI}$ $50.8 \%$ to $68 \%$ ), respectively (fig 1 ). No significant difference in survival was noted between patients with $\mathrm{T} 1(\mathrm{n}=34)$ and $\mathrm{T} 2(\mathrm{n}=$ 89 ) disease, but the five year survival in these groups was $68 \%$ and $58 \%$, respectively. Patients with squamous carcinoma had a five year survival of $69.4 \%$ compared with $52.6 \%$ for those with adenocarcinoma, but this again was not significant $(p=0.1)$. In this group age, sex, and extent of resection made no difference.

In the 40 patients with stage II disease the three and five year survivals were $32.5 \%(95 \%$ CI $18.7 \%$ to $47 \%$ ) and $30 \%$ (95\% CI $15.9 \%$ to $44.1 \%$ ), respectively. Patients with stage II disease with T1N1 lesions had a five year survival of $50 \%$ (95\% CI $37.3 \%$ to $62.9 \%$ ) which was significantly better than patients with T2N1 lesions who had a five year survival of $28.1 \%$ (95\% CI $16.9 \%$ to $39.3 \%, p=0.01$; fig $2)$. The difference in survival between these groups was therefore $21.9 \%$ (95\% CI $5 \%$ to $38.8 \%$ ). Cell type, age, sex, and extent of resection were again insignificant.

Patients with stage IIIa disease $(n=37)$ had a five year survival of $16.2 \%$ (95\% CI $3.5 \%$ to $31 \%$ ). In the 28 patients with $\mathrm{N} 2$ disease the three and five year survivals were $21.4 \%$ and $14.3 \%$. Although this was poorer than for patients with no $\mathrm{N} 2$ nodes $(27.3 \%$ and $17.2 \%)$, the numbers were small and the differences did not reach significance $(p=0.8)$. Cell type, sex, and extent of resection were insignificant.

In the whole patient population $60 \%$ had squamous carcinoma and $30 \%$ adeno- 


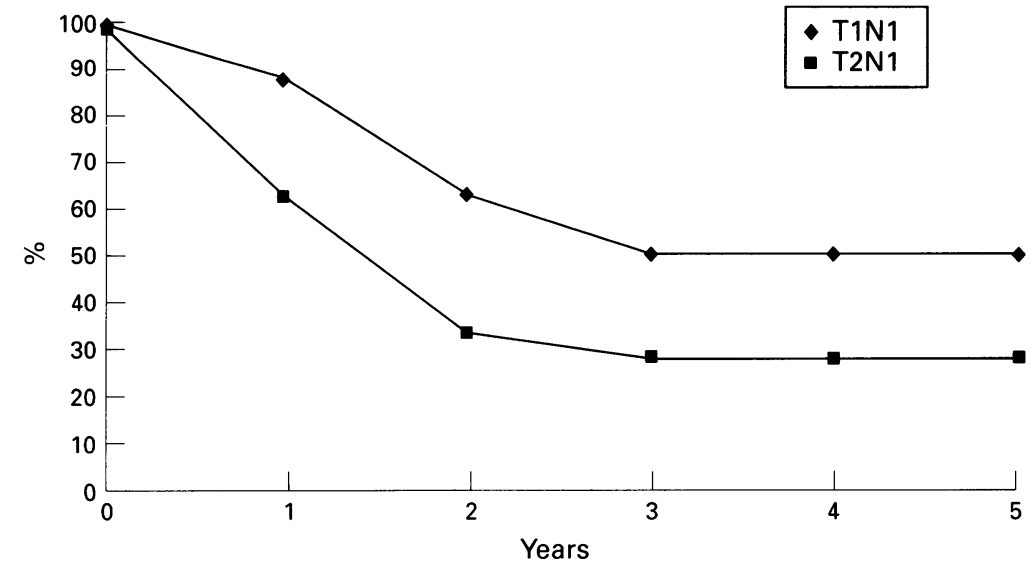

Figure 2 Survival curves within stage II lung cancer for patients with T1N1 and T2N1 tumours. whom the nodes are shown to be involved at preoperative staging. ${ }^{67} \mathrm{We}$, like others, have followed the empirical practice of trying to exclude patients with $\mathrm{N} 2$ disease by preoperative staging but, when involved nodes are encountered at operation, we carry out as extensive a lymphadenectomy as possible in the belief that it remains the best chance of cure. ${ }^{89}$

The possibility of the addition of adjuvant or neoadjuvant therapy to surgery in patients with $\mathrm{N} 2$ disease is the subject of a number of recent and current studies. It has been suggested that adding adjuvant therapy improves survival and that adding neoadjuvant therapy can "down stage" disease to render surgical cure more likely. ${ }^{10-13}$ Both these hypotheses will probably require prospective randomised multicentre if not multinational trials to test them properly, but they are the most encouraging possibilities for improving cure rates in lung cancer currently available.

Postoperative radiotherapy was given to a small number of patients in this study on an ad hoc basis but no conclusions could be drawn about its efficacy. Some authors have suggested a survival benefit from postoperative radiotherapy for patients with $\mathrm{N} 2$ disease $^{14}$ but a recent Medical Research Council trial did not confirm this. ${ }^{15}$

The aim of surgery in this study was to achieve cure by the safest and most conservative procedure possible. There were no differences in long term survival between patients who had lobectomy and those who had pneumonectomy indicating, as others have found, that performing surgery more radical than that required to clear the tumour confers no benefit. ${ }^{716}$ In the short term, however, pneumonectomy was a more dangerous procedure with a higher mortality. Although increasing age as a risk factor after surgery has been a subject for concern,${ }^{17}$ recent studies have indicated that surgical resection is safe in carefully selected patients who are aged over $70 .^{1819}$ The importance of selection in this group is important, however, and, while age was not a risk factor overall in this study, patients over 70 with stage III disease all died within two years.

We conclude that radical resection with the aim of surgical cure is the best available treatment for patients with stages I and II lung cancer and still offers a better chance of cure than any other treatment for patients with stage IIIa disease. The theory that survival in this group might be improved by adjuvant therapy needs to be explored further but is as yet unproven. This study also suggests that there might be a case for subdividing patients with stage II disease according to tumour size and that resection of locally advanced disease in the elderly may not be justified.

1 Mountain CF. New international staging system for lung cancer. Chest 1986;89(Suppl):225-33

2 Naruke T, Goya T, Tsuchiya R, Suemasu K. Prognosis and survival in resected lung carcinoma based on the new international staging system. F Thorac Cardiovasc Surg 1988;96:440-7.

3 Watanabe Y, Shimuzu J, Oda M, Hyashi Y, Iwa T, Nomura A, et al. Proposals regarding some deficiencies in the new international staging system for non small cell lung cancer. fpn f Clin Oncol 1991;21:160-8. volvement (N2 disease) relates to the observation that patients with disease discovered at operation fare better than those in ranged from $6 \%$ to $30 \% .{ }^{45}$ These data raise the possibility that stage IIIa, as it is currently constructed, is a heterogeneous entity.

.


4 Shields TW. The significance of ipsilateral mediastinal lymph node metastasis (N2 disease) in non-small cell carcinoma of the lung. A commentary. 7 Thorac Cardiovasc Surg 1990;99:48-53.

5 Cybulsky IJ, Lanza LA, Ryan MB, Putnam JB, McMurtrey MM, Roth JA. Prognostic significance of computed tomography in resected N2 lung cancer. Ann Thorac Surg 1992; 54:533-7.

6 Watanabe Y, Shimuzu J, Oda M, Hayashi Y, Watanabe S, Tatsuzawa Y, et al. Aggressive surgical intervention in N2 non-small cell cancer of the lung. Ann Thorac Surg 1991; 51:253-61.

7 Van Klaveren RJ, Festen J, Otten HJ, Cox AL, de Graaf R, Lacquet LK. Prognosis of unsuspected but completely resectable N2 non-small cell lung cancer. Ann Thorac Surg 1993;56:300-4

8 Naruke T, Suemasu K, Ishikawa S. Lymph node mapping and curability at various levels of metastasis in resected lung cancer. $\mathcal{F}$ Thorac Cardiovasc Surg 1978;76:832-9.

9 Naruke T, Goya T, Tsuchiya R, Suemasu K. The importance of surgery to non small cell carcinoma of lung with mediastinal lymph node metastasis. Ann Thorac Surg 1988, 46:603-10.

10 Yashar J, Weitberg AB, Glicksman AS, Posner MR, Fen W, Wanebo HJ. Preoperative chemotherapy and radiation therapy for stage IIIa carcinoma of the lung. Ann Thora Surg 1992;53:445-8.

11 Martini N, Kris MG, Flehinger BJ, Gralla RJ, Bains MS,
N2) lung cancer: the Sloan Kettering experience with 36 patients. Ann Thorac Surg 1993;55:1365-73.

12 Rosell R, Gomez-Codina J, Camps C, Maestre J, Padille J, Canto A, et al. A randomised trial comparing pre operative chemotherapy plus surgery with surgery alone in patients with non-small cell lung cancer. $N$ Engl F Med 1994;330 153-8.

13 Roth JA, Fosella F, Komaki R, Ryan MB, Putnam JB, Lee JS, et al. A randomised trial comparing perioperative chemotherapy and surgery with surgery alone in resectable stage III a non-small cell lung cancer. $f$ Natl Cancer Inst 1994;86:673-80

14 Astudillo J, Conill C. Role of postoperative radiation therapy in stage IIIa non-small cell lung cancer. Ann Thorac Surg

15 Medical Research Council Working Party. The role of postoperative radiotherapy in non-small cell lung cancer: multicentre randomised trial in patients with pathologically staged $\mathrm{T} 1-2, \mathrm{~N} 1-2, \mathrm{M} 0$ disease (in press).

16 Martini N. Surgical treatment of lung cancer. Semin Oncol 1990;17:9-10.

17 Harviel JD, McNamara JJ, Straehley CJ. Surgical treatment of lung cancer in patients over the age of 70 years. $\mathcal{F}$ Thorac Cardiovasc Surg 1978;75:802-5.

18 Breyer RH, Zippe C, Pharr W, Jensik RJ, Kittle CF, Fabe LP. Thoracotomy in patients over 70 years. $\mathcal{f}$ Thorac Cardiovasc Surg 1981;81:187-93.

19 Roxburgh JC, Thomson J, Goldstraw P. Hospital mortality and long term survival after pulmonary resection in the elderly. Ann Thorac Surg 1991;51:800-3. 